${ }^{2}$ Nasrallah SM, Iber FL. Mannitol absorption and metabolism in man. Am J Med Sci 1969;258:80-8.

3 Young TK, Lee SC, Tai LN. Mannitol absorption and excretion in uraemic patients regularly treated with gastrointestinal perfusion. Nephron 1980:25:112-6.

4 James JW, Evans RA. Use of oral mannitol in the oedematous patient. Br Med $J$ 1970;i:463-5.

5 Donovan IA. Arabi Y, Alexander-Williams J. Modification of the physiological disturbances produced by whole gut irrigation by preliminary mannitol administration. Br J Surg 1980;67: $138-9$.

Correspondence to Dr M H Winterborn, Department of Paediatric Nephrology, East Birmingham Hospital, Bordesley Green East, Birmingham B9 5ST, England.

Received 5 January 1987

\title{
Brain stem glioma presenting as gastro-oesophageal reflux
}

\author{
M J MAHONY, J D KENNEDY, A LEAF, D J MATTHEW, AND P J MILLA \\ Department of Child Health and Respiratory Unit, Institute of Child Health and Hospital for Sick Children, \\ London
}

SUMMARY Brain stem gliomas may present as gastro-oesophageal reflux. In such cases gastrooesophageal reflux presents atypically late, and computed tomography may not detect the presence of the tumour until late in the course of the disease.

Gastro-oesophageal reflux occurs commonly in infants and typically presents with vomiting soon after birth. Respiratory symptoms associated with aspiration, iron deficiency anaemia with oesophagitis, and failure to thrive are, however, well recognised. ${ }^{1}$ Gastro-oesophageal reflux may also occur in a variety of disorders of the central nervous system, including cerebral tumours. In these latter disorders the presentation of reflux is often atypical. We describe here three children with brain stem gliomas who presented initially with gastrooesophageal reflux.

\section{Case reports}

Case 1. A boy was born at term, with a birth weight of $3150 \mathrm{~g}$. At the age of 8 months he started to vomit. Investigations yielded no abnormality on chest or skull $x$-ray film, barium meal and follow through examination, jejunal biopsy, repeated midstream urine specimen examinations, metabolic screening, and computed tomography. Cerebrospinal fluid was xanthochromic, but subsequent carotid angiography yielded normal results. Vomiting continued and at 11 months physical examination revealed brisk knee reflexes only, with weight $5.7 \mathrm{~kg}(<3 \mathrm{rd}$ centile), height $72 \mathrm{~cm}$ (10th centile), and head circumference $44 \mathrm{~cm}$ (3rd centile). A barium meal examination showed a large hiatus hernia with free gastro-oesophageal reflux, and oesophagoscopy showed oesophagitis. A Nissen's fundoplication was performed. After operation the patient developed stridor and signs of a pseudobulbar palsy. Brain scan showed dilatation of the ventricles, with a tumour mass surrounding the fourth ventricle. Despite a ventricular drain, ventilation, and intensive support, the patient's condition continued to deteriorate and he died.

Postmortem examination confirmed the presence of a large tumour, which filled the fourth ventricle and invaded the medulla, pons, and right cerebellar hemisphere. Both the nucleus ambiguus and tractus solitarius were involved. Histology showed a poorly differentiated glioma.

Case 2. A boy was born normally at term, with a birth weight of $3300 \mathrm{~g}$. At the age of 4 months he developed attacks of breath holding, but he thrived otherwise. By 9 months he was vomiting and experiencing paroxysms of coughing. Investigations, including barium meal, oesophagogastroscopy, metabolic studies, electroencephalography (EEG), and computed tomography, yielded normal results. His symptoms continued and by 12 months he presented as a thin, wasted child with persistent drooling, absent ankle reflexes, tongue furrowed on the left side, and his neck held in extension. His weight was $7.65 \mathrm{~kg}$ ( $<3 \mathrm{rd}$ centile), height $72 \mathrm{~cm}$ (3rd centile), and head circumference $46.5 \mathrm{~cm}$ (25th centile). Blood pressure was 110/70. All investigations, including auditory evoked responses, EEG, computed tomography, and those for Riley-Day syndrome, produced normal results except a barium meal examination, which now showed a dilated oesophagus with disordered motility.

Vomiting continued and because of the ineffective and poorly coordinated peristalsis a Nissen's fundoplication and pyloroplasty was performed at 15 


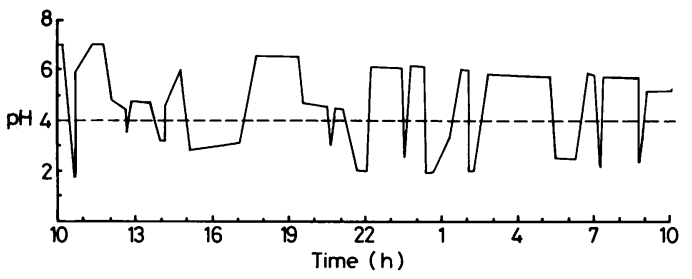

Figure Twenty four hour oesophageal pH study in case 3. Gastro-oesophageal reflux $(\mathrm{pH}<4)$ was present for $28.5 \%$ of the recording.

months. The vomiting resolved after surgery and he started to thrive. His breath holding attacks later became a major problem and at 2.5 years he was reassessed. Neurological examination, a further computed tomogram, and an EEG yielded normal results. The cyanotic attacks and apnoea were thought to be due to severe voluntary breath holding. He died suddenly and unexpectedly at 2 years 11 months. At postmortem examination a tumour was found, involving the upper medulla, invading the floor of the fourth ventricle, and affecting the nuclei of the seventh to 10th cranial nerves. It was shown to be a gangliocytoma.

Case 3. This boy was born at term weighing $3500 \mathrm{~g}$. At 8 months episodes of vomiting and choking developed. Examination revealed generalised wasting only. Extensive investigations, including metabolic screening, jejunal biopsy, chest and abdominal $x$-ray films, upper gastrointestinal endoscopy, microlaryngoscopy, and computed tomography, all yielded normal results. His symptoms continued and at 15 months he weighed $7.5 \mathrm{~kg}(<3 \mathrm{rd}$ centile) and had a height of $76 \mathrm{~cm}$ (10th centile) and a head circumference of $48 \mathrm{~cm}$ (50th centile). Examination produced normal results apart from brisk deep tendon reflexes. A barium meal examination showed a sliding hiatus hernia with gastrooesophageal reflux, which on 24 hour oesophageal $\mathrm{pH}$ study was present for $28.5 \%$ of the time (Figure). A midline posterior fossa mass was found on computed tomography. At operation the tumour had infiltrated the floor of the fourth ventricle and extended down the cervical cord to the second cervical vertebra. A subtotal resection of a grade II astrocytoma was performed. The patient is being followed up as an outpatient.

\section{Discussion}

The three patients described here all presented with vomiting due to gastro-oesophageal reflux, but the timing of presentation was atypically late for infantile reflux.

The pathophysiology of gastro-oesophageal reflux is complex and involves a number of factors, including lower oesophageal sphincter tone, oesophageal motility, and gastric emptying. Resting tone in the lower oesophageal sphincter is largely myogenic but is influenced by neural and humoral factors both in an excitatory and inhibitory fashion. The neural component is composed of extrinsic and intrinsic neural elements. The extrinsic element is almost entirely the vagus nerve, which supplies a network of intramural branches to the distal oesophagus and is largely responsible for sphincter relaxation. $^{2}$

The brain stem may therefore modulate oesophageal motility through vagus nerve projections to the oesophagus. The neurophysiological basis for this has been provided by animal studies in which electrical stimulation of brain stem structures, the dorsal motor nucleus of the vagus, and the nucleus ambiguus resulted in dysmotility of the upper gastrointestinal tract in cats. ${ }^{34}$ The present cases highlight the clinical relevance of these animal studies and are further strengthened by a recent report of the presentation of a brain stem glioma with disordered motility of the upper gastrointestinal tract. ${ }^{5}$ Thus there is both clinical and experimental evidence to support an association between brain stem lesions and disordered oesophageal motility or even hiatus hernia. It has been suggested that the latter is due to contraction of the longitudinal smooth muscle layer of the oesophagus. ${ }^{6}$ Thus if there is disordered extrinsic innervation through the vagus nerve this may well by important in the genesis of the hiatus hernia.

Brain stem tumours present insidiously as the tumour infiltrates between normal neural structures, separating rather than destroying them. Obstruction of flow of cerebrospinal fluid occurs late and the diagnosis is usually suggested by the presence of cranial nerve and long tract signs in the absence of signs of raised intracranial pressure. ${ }^{7}$

In the three patients described here we suggest that tumour infiltration of the brain stem resulted in disordered oesophageal motility with consequent gastro-oesophageal reflux. It was important that the presenting symptoms of reflux in these patients was atypically late, with vomiting developing towards the end of the first year of life. Initially, computed tomograms yielded normal results in all patients, and this emphasises that computed tomography rarely provides adequate delineation of the brain stem to exclude a tumour in the early stages.

We thank Professor R O Weller for the neuropathology report on the patient in case 2 . 
MJM gratefully acknowledges support provided by Janssen Pharmaceutical Ltd.

\footnotetext{
References

1 Jewett TC, Seigal M. Hiatus hernia and gastro-oesophageal reflux. J Pediatr 1984;3:340-5.

2 Cohen S. Motor disorders of the oesophagus. N Engl J Med 1979:307:184-92.

${ }^{3}$ Eliasson S. Activation of gastric motility from the brain stem of the cat. Acta Physiol Scand 1953;30:199-214.

${ }^{4}$ Paganini FD, Norman WP, Kasbekar DK, Gillis RA. Effects of stimulation of nucleus ambiguus complex on gastro-duodenal function. Am J Physiol 1984;246:253-62.
}

5 Wood JR, Camilleri M. Low PA, Malagelada JR. Brain stem tumor presenting as an upper gut motility disorder. Gastroenterology 1985;89:1411-4.

6 Johnson HD. Active and passive opening of the cardia and its relation to the pathogenesis of hiatus hernia. Gut 1966;7:392401.

${ }^{7}$ Hoffman HJ, Becker L, Craven MA. A clinical and pathologically distinct group of benign brain stem gliomas. Neurosurgery 1980;7:243-8.

Correspondence to Dr M J Mahony, Department of Child Health, Institute of Child Health, 30 Guilford Street, London WC1N $1 E H$.

Received 12 December 1986

\title{
Prognosis in Guillain-Barré, syndrome
}

\author{
D M BRISCOE, J B MCMENAMIN, AND N V O'DONOHOE
}

Department of Neurology, Our Lady's Hospital for Sick Children, Dublin, Ireland

SUMMARY Clinical recovery started in 23 children with Guillain-Barré syndrome after a mean time of 19 days and to full recovery in 15 was $6 \cdot 2$ months. Long term follow up indicated that 19 with acute onset had completely recovered clinically and three with subacute onset had a chronic relapsing or protracted course.

Guillain-Barré syndrome was described more than a century ago, but little has been written about the long term outcome in children. Subacute presentation, severe or prolonged illness, profound sensory loss, papilloedema, CSF pleocytosis, gross slowing of nerve conduction, and onion bulb formation on nerve biopsy are associated with incomplete recovery. ${ }^{1-3}$ Most studies deal with adult patients. Eberle et al, however, referring specifically to Guillain-Barré syndrome in childhood, found that if 16 days elapsed without improvement after the weakest point was reached there was a $96 \%$ probability that recovery would not occur, and if the plateau before improvement lasted longer than 18 days incomplete recovery was almost certain. ${ }^{2} \mathrm{Be}-$ cause the patients in that study were followed up for a fairly short time and because our experience has been quite different we report the long term outcome in a well defined group of children.

\section{Patients and methods}

We studied patients admitted to our hospital during the period January 1970 to December 1985 . They were selected according to recommended clinical criteria: progressive motor weakness affecting more than one limb with or without cranial nerve involvement, arreflexia, and absence of pleocytosis. ${ }^{4}$ Twenty four patients (13 male and 11 female aged from 19 months to 13 years (mean age 4 years 7 months)) fulfilled the criteria.

\section{Results}

Twelve patients had had a preceding illness or event, upper respiratory tract infection being the most common (seven cases); the others comprised measles (two cases), mumps (one), infectious mononucleosis (one), and pneumoencephalography for suspected hydrocephalus (one).

Twenty one patients presented acutely (symptoms for three weeks or less before maximum deficit) and three subacutely (symptoms for six weeks or more before maximum deficit). Three patients who presented acutely had the Miller-Fisher variant. ${ }^{5}$ At the time of maximum neurological deficit 10 patients suffered muscle weakness in both arms and legs. This was severe in four, who also had weak diaphragms. Only one patient required ventilation. Eight patients had evidence that the cranial nerves were affected (facial palsy alone in three and multiple cranial nerves affected in five). Six had evidence of autonomic neuropathy manifested as hypertension (three cases), hypotension (one), cardiac arrhythmia (three), profuse sweating (two), and sphincter disturbance (two). The cerebrospinal fluid (CSF) was examined in all patients at least once. A raised CSF protein concentration (mean 1.6 $\mathrm{g} / \mathrm{l}$, range $0 \cdot 1-6.0 \mathrm{~g} / \mathrm{l}$ ) in the absence of a cellular response (less than 10 cells/field) was found in 22 